Critical thinking and teaching have been receiving attention from teachers and researchers in the field of education but, less so, from visual arts teachers. Today's paradoxes - global/local, private/public, identity/difference, knowledge/feelings - require critical theorization in order to help us articulate teaching practices with the social, political and cultural issues that constitute them. This paper presents and discusses three critical proposals to think the curriculum construction in visual arts. Answering to the necessity to especulate and open epistemological ways that offer possibilities for art teachers to engage with critical practices, issues such as 'power', 'knowledge', 'identity', 'daily life' and 'affects' are stressed in this discussion.

Key-words: critical pedagogy, art teaching, curriculum, educational practice, lived experience. 


\title{
Entre contingências e experiências vividas... Propostas para pensar um ensino crítico de artes visuais ${ }^{1}$
}

\author{
Raimundo \\ MARTINS
}

Irene

TOURINHO

O pensamento crítico tem recebido atenção de professores e investigadores do campo da educação mas, em menor grau, dos professores de artes visuais. Os paradoxos que vivemos - global/local, público/privado, identidade/diferença, conhecimento/sentimento - exigem uma teorização que nos ajude a articular práticas docentes com as questões sociais, políticas e culturais que as constituem. Este trabalho apresenta e discute três propostas críticas para pensar o currículo em artes visuais. Respondendo à necessidade de especular e abrir caminhos epistemológicos que ofereçam possibilidades de engajar professores de arte em práticas críticas, questões como 'poder', 'saber', 'identidade', 'vida cotidiana' e 'afetos' têm destaque nesta discussão.

Palavras-chave: pedagogia crítica, ensino de arte, currículo, prática educativa, experiência vivida. 


\section{Buscando conexão...}

Este trabalho está organizado em três arquivos: o primeiro situa, de maneira sintética, momentos de nossa trajetória como alunos e docentes. Diz de onde viemos, onde estamos e de que posição estamos falando. O segundo apresenta e discute três propostas críticas para pensar a construção de um currículo em artes visuais: (1) assumir uma consciência nômade, a capacidade de buscar e operar mudanças (físicas, psicológicas, de grupos, de interesses, de práticas); (2) incorporar uma epistemologia qualitativa na prática docente - qualitativo como uma "política da experiência” (DENZIN, 1997, p. 58), e (3) valorar o 'público’ como espaço de legitimação da prática pedagógica em artes visuais. Junções entre os dois primeiros arquivos nos permitem articular estas propostas com a teoria crítica, tarefa realizada no arquivo III.

A estrutura do texto em arquivos, referência aos softwares de computadores, incluindo os portáteis (nômades?), que se tornaram nossa ferramenta de trabalho, quer mostrar, principalmente, uma escolha e, menos, uma familiaridade com estas ferramentas. De fato, somos "digital immigrants", usando a expressao de Prensky (2005) ao analisar profissionais da nossa geração em contraste com os "digital natives", geração dos 'nascidos' digitais. Organizar o texto em arquivos significa compreender que idéias e conceitos transitam entre ou migram de um arquivo para outro. Significa, ainda, acreditar na possibilidade de que novos arquivos sejam criados e/ou vinculados a estes. Mesmo circunscrito às condições de tempo e lugar, um texto pode ser um convite ao diálogo, à circulação de idéias, pois ler não é uma atitude passiva e, sim, interativa. Este texto faz este convite.

Anexado ao arquivo II seguem duas notas de caução. A primeira, mais importante, diz respeito à intenção do texto. Escrevemos para reunirmo-nos com outros autores e leitores. Lembramos, então, que não consideramos as propostas que apresentamos como suficientes ou prioritárias para a construção de um currículo em artes visuais, uma prática pedagógica crítica. Entretanto, acreditamos que elas têm força produtiva - conceitual, metodológica e prática, condição que as qualifica para a discussão e o diálogo. Ao reuni-las, nossa intenção é oferecer uma 
contribuição e provocar a continuidade do debate que inscreve o ensino de artes visuais numa perspectiva crítica.

A segunda caução refere-se a exemplos que contam de significados e experiências de ensino de arte vividas na Espanha. Além da proximidade que eles têm com experiências educacionais de outros países, a utilização desses exemplos também resulta do fato de estarmos escrevendo, neste momento, estimulados pela oportunidade de aprender e contar histórias da Espanha, país onde estamos vivendo e estudando.

Entre as diferenças e semelhanças das nossas histórias (lembrando que há os que acreditam, como nós, que os seres humanos têm mais semelhanças que diferenças... um 'mais' que não implica perda da importância da 'diferença') - como indivíduos, gênero, geração, profissão, etc. - traçamos estes caminhos como uma opção para seguir viagem, trilhar outras veredas, explorar novas rotas e roteiros, fazer novos planos e propostas.

No arquivo I, começamos a viagem por nós mesmos: uma narrativa que - conforme escrito acima - situa pedaços de quem somos e esclarece a partir de que posições construímos nossas propostas. Damos pulos e andamos lado a lado. Omitimos e 'descobrimos' algumas experiências. Agimos como alunos, docentes e investigadores, condições que nos caracterizam profissionalmente. A narrativa inicial recupera alguns contextos que nos formaram, tentando a conexão que buscamos...

\section{Arquivo I: Circunstâncias...}

Este arquivo remonta partes de nossas 'histórias escolares'. Não pretende ser um relato biográfico, nem uma 'história de vida' no sentido que Goodson define, mas almeja enfrentar a importância que as experiências vividas e as questões de 'identidade' vêm assumindo na teorização curricular das últimas décadas. Conforme destaca Goodson, "a agenda a nossa frente é aquela na qual identidade e experiência vivida podem, elas mesmas, ser usadas como sítios onde e a partir dos quais nós interrogamos teórica e criticamente o mundo social". Para este autor, "as políticas de vida e as políticas da construção e manutenção contínua de identidades se tornarão o mais crescente sítio de con- 
testação ideológica e intelectual" (GOODSON, 2005, p. 1). As situações e percepções que expomos neste arquivo têm este caráter de servir para combater a "atitude de ocultação" que tem marcado os escritos de professores, conforme observa Hernan$\operatorname{dez}(2004$, p. 17).

Somos "efeitos" de como vamos nos formando e "já não é possivel dizer que 'nos tornamos o que somos' e, sim, que 'somos o que vamos nos tornando"' (TOURINHO, 2005, p. 118). A 'atitude de ocultação' a que nos referimos é analisada por Hernandez que a considera importante o suficiente para se tornar "tema de um estudo". Em sua análise, Hernandez comenta que

não têm sido muitos os professores que têm decidido contar sua história na primeira pessoa. Existe um certo pudor católico que evita ou freia que isto seja possível. Às vezes, nas páginas das revistas de educação (...) aparecem experiências cotidianas de docentes com seus alunos. Mas são experiências sem sujeitos. Na maioria dos casos, as crianças e adolescentes aparecem somente desde sua dimensão de alunos. Enquanto o professor se oculta na sombra, permanece no anonimato de seus pensamentos e vivências. Conta o que faz, mas diz pouco sobre o que vive e aprende em sua experiência, em seu trajeto profissional/pessoal (2004, p. 17).

Perder o anonimato através das histórias que contamos tem para nós um duplo sentido: aprofunda nossas afinidades em termos de questionamentos, preocupações e ideais profissionais e, de maneira mais ampla, nos conecta intersubjetivamente com colegas professores, investigadores, autores e alunos. Escrever a quatro mãos - a duas cabeças - não é tarefa fácil mas como filhos de professoras, que ambos somos, guardamos um firme e persistente desejo de aprender.

Produtos de uma escolarização católica - colégio de freiras e padres - nossas aulas de arte nos anos 50 e inícios de 60, eram preenchidas por trabalhos manuais que compreendiam cópia de desenhos e ornatos, feitura de enfeites, recortes e colagens, trabalhos com cor e, às vezes, exercícios de sombra. Começávamos a ser 'escolarizados'. Numa escola, só meninas; a outra, mista. Geometria e Desenho Técnico eram disciplinas que reprovavam, diferentemente das outras atividades artísticas. Sob a ditadura militar (1964), aprendemos - e posteriormente ensinamos - 
Entre contingências e experiências vividas...

Propostas para pensar um ensino crítico de artes visuais

danças e canções do folclore nacional, os hinos pátrios, cantigas de roda e jogos populares. Os trabalhos manuais persistiam, mas as aulas de música ganhavam mais espaço curricular.

As aulas de música produziam menos bagunça na sala, apesar do ruído, apenas tolerado por alguns professores. A maioria dos professores de artes dos primeiros anos - geralmente mulheres - eram autodidatas, 'talentosas' e dedicadas ao ofício. Gostavam de arte e de ensinar, porém, não tinham formação pedagógica. Até o início da década de 70 não havia, no Brasil, nenhum curso superior para formação de professores de arte. As freiras tinham educação belga e promoviam peças teatrais, corais e 'bandinhas' que eram apresentadas no teatro da escola, de 600 lugares. Coisa de muita magia para nós, alunas. Os padres eram jesuítas, quase todos vindos de Portugal. Primavam pelo rigor disciplinar e enfatizavam os estudos 'acadêmicos'. A música não tinha tanta importância quanto a literatura. Havia um Grêmio Lítero-Musical que se concentrava em leituras dramáticas de textos da literatura 'clássica' ocidental: líamos os filósofos gregos, passávamos por Shakespeare, Camões e chegávamos a Castro Alves e José de Alencar. Apesar da menor importância da música, os professores eram severos em sua preocupação com a entonação correta para a leitura dos textos dramáticos.

As salas de aula do colégio das freiras eram grandes, arejadas e bem equipadas. A limpeza era impecável. Os pátios eram amplos, com equipamentos para jogos e brincadeiras. Tinha uma piscina e uma área arborizada, coisa considerada necessária naquele sertão do país. Francês e Inglês eram disciplinas obrigatórias e a filosofia era parte do currículo desde o ginásio (atual Ensino Fundamental). Os padres do Educandário faziam provas escritas e orais e as sabatinas eram semanais.

$\mathrm{Na}$ nossa trajetória estudantil, só depois de incorporados aos hábitos da escolarização é que tomamos consciência de que a escola reflete e refrata a realidade social, o contexto do qual faz parte. Freqüentamos escolas de classe média e alta, fato que altera o enredo de nossas vivências pois coloca ensino, professores, materiais escolares, oportunidades, espaços físicos e ambientes de aprendizagem em outro diapasão social e cultural.

Também relembramos do período de quase uma década em 
que estudamos nos Estados Unidos como alunos de mestrado e doutorado, cada um em seu momento, distante quase 10 anos um do outro. Experimentamos viver em outra cultura, enfrentar a pressão para produzir e a competitividade, numa língua distante da nossa. As marcas de alunos se misturavam com as experiências docentes pois começamos a lecionar muito cedo um com 17 (Raimundo) outro com 15 (Irene). Nos perguntamos quais eram nossas preocupações naqueles tempos e quais ainda permanecem, que motivações nos impulsionaram e nos mantém na profissão.

Enquanto revíamos nossas histórias para escrever este trabalho, rastreamos os contextos de desigualdades que marcam o nosso país com visíveis distinções de classe social, cultural e uma das piores distribuições de renda do planeta. Ampliar as condições de acesso e participação cultural dos alunos é uma das preocupações que nos une e continua nos orientando. Nos estimula ver crescer o espaço e a importância das artes na educação mas, como qualquer processo educativo, todo crescimento é lento, difícil e caro.

Os ideais que perseguíamos ainda permanecem grudados em nós. Tomam outras formas, ganham novos nomes mas, no fundo, docência e investigação continuam sendo para nós uma questão de compromisso humano, ético, ideológico e político. Falar desses compromissos significa refletir e rever continuamente nossas histórias mas, para responder ao desafio de construir propostas críticas para um currículo de educação em artes visuais sentimos necessidade de iniciar esta reflexão com lembranças de histórias da educação que vivemos. Assim, nossas vozes e timbres podem se misturar, dando às propostas que apresentaremos um som amplificado, de coro misto com múltiplas vozes.

\section{Arquivo II: Propostas...}

As propostas que este arquivo apresenta para pensar um currículo em educação das artes visuais foram inspiradas principalmente por idéias de autores como Cary (1998), Denzin e Lincoln (2003), Efland, Freedman e Stuhr (2003), Giroux (1995), Hernandez (2005), Kincheloe e McLaren (2003) e Silva (2001). Estes/as autores historiam, caracterizam e discutem a teoria, a 
investigação e a pedagogia crítica.

A elaboração do pensamento sobre o constructo "crítico", além de elos com as teorizações neo-marxistas, especialmente aquelas advindas da Escola de Frankfurt (APPLE, 1990; FREEDMAN, 2003), encontra suporte nas idéias de Paulo Freire $(1991 ; 1996 ; 2004)$ e se expande com as influências e transformações propostas pelas viradas cultural (HALL, 1997) e narrativa (DENZIN \& LINCOLN, 2003) que demarcaram novos horizontes discursivos, teóricos e práticos conectados ao poder, à vida cotidiana e às sensibilidades mundanas constituídas de afetos que nos subjetivam e diferenciam. Vários "pós” participam destas concepções críticas - pós-modernismo, pós-estruturalismo e pós-colonialismo, além do deconstruccionismo, dos estudos culturais, estudos feministas e outros. Através dessas teorizações, maneiras de pensar, sentir e fazer uma educação crítica são esboçadas, questionadas e impulsionadas.

Entre as idéias que dão suporte ao pensamento crítico e contribuem para as propostas que apresentaremos, destacamos as seguintes:

(a) uma preocupação com a justiça social através do 'empowerment' e emancipação dos oprimidos (CARY, 1998, p. 9);

(b) um posicionamento dialético - divergente, diríamos em relação à construção social da experiência (KINCHELOE e MCLAREN, 2003, p. 435);

(c) a necessidade de entender os vários e complexos modos como o poder opera para dominar e formatar a consciência (KINCHELOE e MCLAREN, 2003, p. 439);

(d) a proliferação de epistemologias interpretativas fundadas nas experiências vividas de grupos previamente excluídos no mundo global pós-moderno (DENZIN, 1997, p. 53);

(e) a importância de se compreender a escolarização como um mecanismo de poder, negociação e contestação (BENNET apud GIROUX, 1995, p. 87);

(f) a rejeição da noção de pedagogia como uma técnica ou um conjunto de habilidades neutras e sua reafirmação como uma prática cultural que só pode ser compreendida através de questões sobre história, política, poder e cultura (GI- 
ROUX, 1995, p. 87).

De uma maneira abrangente, o pensamento crítico analisa possibilidades, origem, valor, leis e limites do chamado conhecimento racional, como ponto de partida para uma reflexão filosófica e pedagógica. Saber, poder e identidade estão inter-relacionados nesta reflexão que questiona quais saberes são selecionados para o currículo, como, por quem e para quem (além das outras questões: por que?, por quanto tempo?, para que?). Apesar da proliferação de discursos pautados por um posicionamento crítico - educação crítica, pedagogia crítica, currículo crítico, ensino crítico, compreensão crítica, etc. - ainda causa espanto a pouca teorização existente na área do ensino das artes visuais.

Sousa Santos nos conta de uma pergunta que o "persegue desde há alguns anos": "havendo tanto por criticar no mundo, porque se tornou tão difícil construir uma teoria crítica?" (2005, p. 11). As propostas que apresentamos têm o caráter de contribuir para atar e reatar vínculos entre pensamento crítico, currículo e artes visuais. Vivemos num tempo em que é necessário "transformar a ciência em política da experiência" (DENZIN, 1997, p. 58). As epistemologias que partem desta idéia movimentam-se, como nos diz Denzin, em duas direções simultâneas. Uma em direção à "descoberta de conhecimento sobre o mundo social, a forma como este mundo busca entranhar-se na vida das pessoas oprimidas". A outra tenta "rever e dar valor ao conhecimento que tem sido suprimido pelas epistemologias existentes nas ciências sociais" (DENZIN, 1997, p. 58). Estas duas direções abrem caminhos para situações que são pessoais e coletivas, para experiências nas quais o poder silencia ou exclui conhecimentos que tanto alunos quanto professores, através de suas vivências, em tempos, lugares e circunstâncias diferentes, podem reconhecer e reconstruir.

A reflexão sobre nossas histórias, diálogos com outras histórias do ensino de arte e com teóricos críticos, apontam, como primeira proposta, para a necessidade de incorporar um espírito viajante como matéria prima para um currículo crítico em artes visuais. No sentido literal, essa idéia nos faz lembrar, por exemplo, do professor de Garcia Lorca na disciplina teoria da 
literatura e das artes, na Universidade de Granada, Espanha. O professor incluía, como parte do programa, viagens de estudos por diferentes cidades da Espanha. A primeira publicação em prosa de Garcia Lorca, "Impresiones y Paisajes", é um relato de viagens feitas em razão daquela disciplina (ALVAREZ, 1998). Itinerários, eixos e caminhos de um programa de ensino podem levar - e passear - por múltiplos lugares e paisagens.

Impregnado de um espírito viajante, um currículo crítico busca provocar deslocamentos no tempo e no espaço vinculando fazeres, olhares e sentidos a temporalidades locais, contextualizadas. Tal espírito não se limita a provocar mas, também, a pensar deslocamentos. Essa primeira proposta enfatiza, então, a necessidade de uma atitude radical para assumir uma consciência nómade. Segundo Braidotti,

a consciência nômade consiste em não adotar nenhum tipo de identidade permanente. O nômade só está de passagem: ele/ela estabelece essas conexões necessariamente situadas que lhe ajudam a sobreviver, mas nunca aceita plenamente os limites de uma identidade nacional, fixa. O nômade não tem passaporte; ou tem muitos (2000, p. 74).

O espírito viajante é aliado da consciência nômade mas, como nos esclarece Braidotti,

esta idéia de estar de passagem, de atravessar diferentes tipos e níveis de identidade não é uma maneira de fugir da confrontação com as reais pressões ideológicas e sociais sob as quais cada um deve mover-se. Muito pelo contrário, a consciência nômade expressa uma maneira de afrontar essas pressões (p.75, grifo nosso).

Um currículo crítico, viajante nômade, também não se deixa instalar numa visão teórica. Provocação, conhecimento e transgressão são linhas da mesma trama que esta proposta para construção de currículo quer tecer. Ainda nas palavras de Braidotti, "a identidade do nômade é transgressora e sua natureza transitória é precisamente a razão pela qual pode fazer conexões" (p. 77).

Este currículo enuncia pactos com modos múltiplos de posicionamentos de sujeitos, sem delimitá-los em territórios 
conceituais, epistemológicos ou políticos. Enuncia pactos com produções tanto da chamada alta cultura quanto da cultura popular ou quaisquer outras manifestações, mesmo aquelas ainda não rotuladas. Permite, neste sentido, lidar, como fez Gombrich, tanto com a mitologia clássica nas obras renascentistas quanto com manuais para passageiros de avião (CONDURU, 2005). As fontes visuais desse currículo estão em muitas partes: museus, galerias, shopping centers, Internet, ateliês de artesãos, "imagens de informação, publicidade e ficção" (AUGÉ, 2003, p. 34). Estão nas casas, nas ruas, nas escolas, nos livros, nas cabeças.

Em O Currículo como Fetiche, Tadeu da Silva argumenta que "é nossa tarefa e nosso trabalho, como educadores críticos/as, abrir o campo do social e do político" - e, no nosso caso, o campo do visual - "para a produtividade e a polissemia, para a ambigüidade e a indeterminação, para a multiplicidade e a disseminação do processo de significação e de produção de sentido" (2001, p. 9). Transgredir e transitar são funções docentes. Como sugere Tadeu (2003), "é preciso perguntar como se pode pensar o intratável, o impensável, o não-pensado do pensamento curricular, a exterioridade, o diferente de si, o seu outro?" (p.32). Na proposta que ora apresentamos, o pensar não está apenas conectado a uma "ação informada, dirigida a contestar processos de dominação profundamente incorporados nas nossas vidas cotidianas" como sugere Cary (1998, p. 13). O pensar se conecta também a processos de poder nos quais nem sempre a dominação é visível e nem sempre seus processos estão incorporados, pois o poder também se transforma através de muitos, complexos e desconhecidos níveis e 'operações' fazendo-se presente em qualquer relação.

Um currículo crítico para as artes visuais busca contestar, ainda, as maneiras como a razão-poder opera para privilegiar certos tipos de conhecimento, fazeres e formas de compreensão artística. Viajante nômade, este currículo fareja múltiplas camadas de significados que ligam sujeitos, objetos e manifestações artísticas em contextos de aprendizagem e ensino. Camadas que não apenas refazem ou desconstroem mas também criam significados, novas trilhas de relação e de experiência em processos nos quais todo conhecimento é auto-conhecimento (Sousa San- 
tos, 1999). Isso significa olhar para várias direções, rever nossas próprias histórias e convicções refletindo - através de lentes teóricas e experienciais diversas - sobre as maneiras como elas se formam e podem se transformar.

Este currículo, além de nos 'autorizar' a lidar com qualquer tipo de imagem, abre-se ao espectro de significações e contextos implicados em cada uma delas. "Las Meninas", de Velásquez, por exemplo, articula um espectro de significações e contextos quando colocado em diálogo com os estudos sobre "Las Meninas" de Picasso e as esculturas de Manolo Valdéz, inspiradas no mesmo trabalho. Estas possibilidades de viagem apontam para o fato de que "o interessante hoje é pensar a arte enquanto instância crítica da realidade. Ela pretende ser algo que está no mundo, mas que critica os modos de agir e pensar desse mundo" (CONDURU, 2005, p. 5).

Antes de seguir para a segunda proposta, ressaltamos que este currículo é criativo pois é capaz de reinventar a si próprio a partir de abordagens e práticas que rompem fronteiras disciplinares, fazem bricolagens conceituais e estéticas e utilizam, por empréstimo, noções e imagens que pertencem a outros contextos de origem. A criatividade de um currículo crítico é radical no sentido que ele próprio é visto como uma 'invenção', algo que é feito, vivido e re-feito "ao vivo", na relação entre os sujeitos que o confeccionam (CORAZZA, 2001). É uma criação conectada com percepção e imaginação pois enfatiza a fusão entre estas dimensões.

A segunda proposta para um currículo crítico é a incorporação radical da perspectiva qualitativa no ensino de artes visuais. A importância desta perspectiva resulta de sua capacidade para lidar não apenas com nossa condição híbrida e mutante mas, principalmente, por trabalhar com um olhar contextualizado, singularizado e interpretativo, sobre as situações e acontecimentos do cotidiano da escola, das experiências que ali são vividas.

A radicalização do 'qualitativo' como pulsão de um currículo crítico atrai e dilata possibilidades expressivas da linguagem, multiplicando as vozes que falam e brincando de achar maneiras mais contingentes, circunstanciais e poéticas de narrar e refletir sobre o que se faz - e não se faz, se pensa e sente no ensi- 
no de arte que acontece nas escolas. A qualidade da experiência daqueles para quem o desenho é um relax, referendou olhares sobre aulas de arte durante muitas décadas, em vários países (PASTOR, 1998). Através de qualidades ligadas às práticas de trabalhos manuais como, por exemplo, durante o franquismo passividade, submissão, sacrifício - este período torna-se particularizado e podemos configurar disposições e práticas que ele encarnava em muitos sujeitos que o vivenciaram (MIRAVALLS, 1998).

A perspectiva qualitativa "não determina como vemos o mundo mas nos ajuda a projetar questões e estratégias para explorar o mundo" (KINCHELOE e MCLAREN, 2003, p. 436). É assim que "o belo" leva Ruiz e Malanda a se aproximarem da educação artística de mulheres, explorando um mundo em que "a Igreja foi determinante (...) na hora de atrasar o desenvolvimento da instrução feminina na qual viam um perigo para a sustentação da tradição e da vida familiar, social e nacional" (2001, p. 382). No Brasil, não foi diferente.

A incorporação da perspectiva qualitativa não se limita à prática investigativa. Abarca a aprendizagem e o ensino, e questiona o processo de "ditatorializaçao" do sujeito que se dá inclusive pelos muitos olhares a partir dos quais estamos vendo, controlando, medindo, despindo e vestindo nossas subjetividades. Aprender e ensinar a partir desta perspectiva significa deter-se - para debater e interrogar - nos tipos de investimentos afetivos que são escolhidos e despendidos entre e com os sujeitos nas salas de aula. Martins acrescenta que "significados e experiência, devem estabelecer relações de tradução, ou seja, processos de conversão do conceitual em experiência ou da experiência em conceitos" (2005, p. 142). A perspectiva qualitativa num currículo de artes visuais vê imagens, produtos, objetos, manifestações, mas busca olhares sobre os sujeitos que interagem com estas imagens. Não se satisfaz com a idéia de falar 'sobre' imagens mas quer explorar maneiras de falar 'com' imagens e de fazer que elas falem sobre nós.

Filiada a uma tradição hermenêutica, a perspectiva qualitativa dá destaque à interpretação e à experiência vivida. Como pesquisadores, docentes e alunos, fazemos histórias com as nos- 
Entre contingências e experiências vividas...

Propostas para pensar um ensino crítico de artes visuais

sas próprias vidas e vivemos encharcados de significados que nem sempre são os que escolhemos para nós mesmos. Em sua discussão sobre a investigação educativa e a experiência vivida, Van Manen chama a atenção para o fato de que estas experiências "acumulam importância hermenêutica quando nós, ao refletir sobre elas, as unimos ao recordá-las" (2003, p. 57). Para ele, "a experiência vivida é a respiração do significado. No fluxo da vida, a consciência respira significado num movimento de vai-e-vem: uma tensão constante entre o interno e o externo (...)" (p. 56).

As armadilhas desta tensão entre o interno e o externo têm sido abordadas por poetas e escritores. O poeta paranaense Leminski, denuncia: "tudo que respira, conspira". Este vai-e-vem da consciência inclui uma tensão entre estar só ou estar acompanhado, tensão que Luis Fernando Veríssimo (2005, p. 3) descreve de maneira jocosa:

Partículas subatômicas

se comportam de um jeito

quando são observadas

E de outro quando estão sós.

Como, aliás, todos nós.

Isso não significa que haja oposição entre sujeito individual e social. Como esclarece Corazza, eles "não se opõem entre si como entidades absolutas, cada qual exigindo a dissolução do outro, mas estão vinculados numa história comum: a da individuação, seja ela coletiva ou particular" (2001, p. 62). A relação entre "interesses individuais" e "necessidades coletivas" é resultado de um outro tipo de tensão, aquela entre "emancipação e regulação", como nos explica Monedero (2005) em sua detalhada análise das idéias do sociólogo português Sousa Santos. Monedero apresenta e discute estes conceitos contextualizando-os em relação à modernidade e à "pós-modernidade de oposição" - posicionamento do sociólogo Sousa Santos. Extensa, a citação seguinte oferece uma clara explicação da tensão a que estamos nos referindo:

Como foi ressaltado, toda a vida social (e a reflexão política) está atravessada pela tensão entre interesses individuais e necessidades 
coletivas. Esta tensão entre emancipação e regulação foi resolvida na modernidade através de uma forma de racionalização da vida social que tentava construir uma tensão virtuosa entre valores incompatíveis, ao menos potencialmente: autonomia individual e justiça social; liberdade particular e igualdade coletiva.

A regulação social e a emancipação social eram as encarregadas de harmonizar esses valores, utilizando os recursos do Estado, do mercado e da comunidade, assim como as três racionalidades assinaladas por Weber, isto é, a racionalidade estético-expressiva (o campo da expressão onde se inclui a arte), a racionalidade cognitivo-instrumental (o campo técnico e científico) e a racionalidade moral-prática (o campo normativo). O direito e a ciência se encarregaram de dissolver os excessos e os déficits da regulação e da emancipação com o fim de manter a tensão entre ambos princípios, mas terminaram colonizando as demais lógicas, especialmente a arte e a ética (MONEDERO, 2005, p. 48).

O autor segue discutindo como o 'direito' e, especialmente a 'ciência', se transformaram em mercadoria, relegando a arte e a ética a um plano secundário. A tensão entre interno e externo, entre emancipação e regulação coloca as histórias de professores, investigadores e alunos num contexto social e cultural onde respirar, conspirar, estar só, ser observado e interagir são realidades que estas histórias fazem significar no mundo de experiências vividas.

Ver o mundo qualitativamente nos faz interrogar e questionar estas realidades tentando integrá-las e recriá-las com as visões e vozes daqueles que não falaram, que foram silenciados ou excluídos. Nos faz colocar, em termos de investigação, a "ênfase na natureza socialmente construída da realidade, na inter-relação íntima entre pesquisador e foco de estudo e nas limitações situacionais que conformam a investigação" (DENZIN \& LINCOLN, 2003, p. 13). Em termos de prática pedagógica, podemos parafrasear Denzin \& Lincoln para estender a concepção qualitativa à prática docente, colocando, assim, a "ênfase na natureza socialmente construída da realidade, na inter-relação íntima entre" docente e 'feixe' de ensino "e nas limitações situacionais que conformam a prática pedagógica” (grifos nossos).

Se um currículo nômade, 'vagamundo' - como sugerem Corazza e Tadeu - dá preferência à diferença em relação à identidade, estimula a invenção em lugar da revelação e celebra "os 
Entre contingências e experiências vividas...

Propostas para pensar um ensino crítico de artes visuais

prazeres - e até mesmo os perigos - da confusão de fronteiras" (CORAZZA e TADEU, 2003, p. 11-12), um currículo qualitativo reforça "a intimidade da relação entre conhecimento e ação" reinstaurando "a experiência vivida como uma base válida para a ação prática" e "dirigindo-nos para um sentido pessoal e vivido do conhecimento" (VAN MANEN, 2003, p. 170).

A terceira e última proposta crítica que concebemos para pensar um currículo em artes visuais, prolonga os sentidos do currículo nômade e do currículo qualitativo para mergulhá-los no espaço público onde eles se fazem e acontecem. A proposta é privilegiar radicalmente, a esfera comum, pública, das experiências educativas e visuais. A necessidade de privilegiar o caráter público da educação e das visualidades está atrelada a reflexões de ordem social, ética e política. Dissociar o aprender e o ensinar da esfera pública é negar o caráter colaborativo do conhecimento, a dimensão construtiva da compreensão e a condição participativa do desenvolvimento e transformação do humano. Conforme afirma Hannah Arendt,

nenhuma atividade pode tornar-se excelente se o mundo não proporciona espaço para seu exercício. Nem a educação nem a engenhosidade nem o talento pode substituir os elementos constitutivos da esfera pública, que fazem dela o local adequado para a excelência humana (1995, p. 59).

Privilegiar a esfera pública significa colocar em evidência o compromisso com relações igualitárias entre sujeitos, com a cidadania e a colaboração na construção de um mundo justo, com qualidade de vida. A pedagogia crítica reconhece as lutas a serem enfrentadas para conseguir a meta maior que é a igualdade social. Nosso compromisso como educadores críticos é com o processo transformador e com o reconhecimento de que esta transformação depende de um trabalho contínuo de auto-reflexão e, como nos ensina Paulo Freire, depende também de uma 'esperança' no valor humano da convivência e da aprendizagem.

A reunião desses compromissos nos faz alcançar outros espaços para pensar o currículo a partir de vínculos entre instituições públicas diversas. A idéia de que "existem outras instituições que educam e a escola, que esteve acostumada a ser fi- 
lha única,(...) tem que compartilhar e ter algo interessante para dizer, porque, caso contrário, ninguém vai escutá-la" (BACCEGA, 1998, p. 14) é uma parte desta busca por novos entornos de aprendizagem e ensino. É com este espírito por exemplo, que Padró se interessa por "especular quais são as posturas e posições daqueles profissionais que mediam a construção de significado nos museus" (PADRÓ, 2003, p. 23). Um dos dez entrevistados de seu estudo afirma que "em geral, (...) as instituições museísticas entraram na cultura do espetáculo e do entretenimento deixando para trás implicações mais profundas (...)" (2003, p. 36). Para Padró,

nenhum desses sujeitos tem em conta que a educação nos museus pode contribuir para mudar o sentido das instituições museísticas ou que as práticas diárias dos departamentos de educação também podem ser catalisadoras ou reinventar as políticas do cotidiano (2003, p. 37).

Cientes de que a educação não é uma atividade neutra, descontextualizada, nos perguntamos: onde nos encontramos neste início de século? Que experiências estão nos marcando?

José Marina (2004), filósofo espanhol, resume estas preocupações afirmando que "vivemos paradoxos que resultam difíceis de manejar". Sem nos deter para analisar cada um deles, como faz o filósofo, revê-los neste momento, reunidos, pode nos ajudar a dar um sentido intenso a eles:

- O mundo se globaliza e se nacionaliza simultáneamente;

- Aumenta a produção de bens, mas diminui o trabalho;

- Vivemos em uma sociedade tecnológica, mas desconfiamos da tecnologia;

- Confiamos parte de nossa liberdade aos políticos, mas desconfiamos deles;

- Não sabemos se estamos progredindo ou retrocedendo;

- Cremos que o conhecimento é importante, mas são os sentimentos que nos fazem felizes ou desgraçados (p. 24-27).

Estes paradoxos finalizam com uma dimensão geralmente entendida como privada - a dos sentimentos. A importância das emoções é interesse de investigadores fora do campo da arte. Alzina, por exemplo, ressalta que "a maioria dos problemas com 
Entre contingências e experiências vividas...

Propostas para pensar um ensino crítico de artes visuais

os quais os estudantes atuais se encontrarão tem mais a ver com (...): prevenção da violência, consumo de drogas, aids, condução temerária, stress, depressão, suicídio, violência doméstica, vandalismo, etc", do que com conteúdos específicos das disciplinas. Para ele, "estas são necessidades que não são suficientemente atendidas nas áreas acadêmicas comuns" (ALZINA, 2003, p. 323).

Marçal (2001) discute vínculos entre emoção e arte como parte de uma história na qual o existencialismo tem importância fundamental. Passando em revista as visões atuais sobre a emoção, ela se reporta a Denzin quando diz que "para compreender quem é uma pessoa, é necessário compreendê-la emocionalmente" e que "conhecer-se a si mesmo é a primeira regra para um bom domínio da classe" (apud MARÇAL, 2001, p. 254). Compreendemos que a primeira regra tem valor agregado a outras regras pois não há um estado da experiência vivida no qual o sujeito possa dizer que "conhece a si mesmo", ou que "conhece o outro".

Porém, a radicalização do público no currículo compreende os sujeitos que vêem, lêem, ouvem, falam, sentem, dão atenção, são 'alvo' e dialogam com 'imagens', gestos e informações como constituídos nestes espaços, como 'efeitos' das relações que se dão no espaço público. Os sentimentos, portanto, são parte dessa construção colaborativa, social, que permite, reprime, controla, excita e configura nossas expressões, emoções e conhecimento (BOLER, 1999).

A separação crescente entre os domínios do intelecto e do sensível, uma concepção redutora do conhecimento, nos levou a este olhar de superioridade do primeiro sobre o segundo. A desconexão entre conhecimento intelectual e sensível é discutida por Duarte Jr. (2001) que vê "nefastas decorrências (...), notadamente uma espécie de esquizofrenia que isso acarreta nos comportamentos diários, seja dos intelectuais, seja de todos nós, seres humanos comuns" (165). Sua reflexão nos atenta para o fato de que

evidentemente, o conhecimento ampliou tanto os seus domínios, para regiões tão distantes quanto imensas, tão minúsculas quanto invisíveis, que uma referência direta sua à vida cotidiana parece ser 
mesmo coisa impossível. Contudo, o que se questiona é o seu total apartamento da vida ao menos da vida diária do cientista e a incapacidade deste em discutir e articular o tipo de conhecimento que produz à vida social maior (167).

Uma pluralidade de estruturas sociais que se interconectam criando múltiplas culturas, espaços e práticas que envolvem família, escola, igreja, imprensa, grupos étnicos, etc., caracteriza as sociedades contemporâneas. Nessas comunidades, as relações se mesclam e entrecruzam enfraquecendo e, em algumas situações, quase apagando as distinções entre público e privado, civil e cívico, comum e particular (DENZIN, 1997). A "incapacidade" do pesquisador - como nota Duarte Jr. - para "discutir e articular o tipo de conhecimento que produz à vida social maior" é parte da condição que o sentido e o sentimento público no trabalho da educação pretende combater.

O cotidiano plural sobre o qual estamos falando é descrito por Denzin como a "postsurveillance society", situação típica de um mundo conectado a, e emaranhado em muitas esferas sociais. Nesse mundo, o cotidiano transforma-se em espaços culturais onde sujeitos dialógicos transitam, se deslocam através de narrativas e de associações públicas e privadas com o outro. Entretanto, como nos adverte Hannah Arendt,

o fato de uma atividade ocorrer em particular ou em público não é, de modo algum, indiferente. Obviamente, o caráter da esfera pública muda segundo as atividades que nela são admitidas, mas, em grande parte, a natureza da própria atividade também muda (1995, p. 56).

\section{Arquivo III: Rumos...}

Os paradoxos contemporâneos, em especial a separação entre conhecimento intelectual e conhecimento sensível e a proliferação de estruturas e comunidades sociais imbricadas em múltiplos espaços culturais solicita uma mobilização e engajamento de docentes e investigadores para reafirmar o caráter público que distingue a educação visual e as possibilidades que ela concretiza para a transformação. Seguindo Hannah 
Arendt, nos perguntamos: De que maneira o caráter público se distingue ao acolher a educação? De que maneira a natureza dos processos de aprender e ensinar se alteram por serem parte da esfera pública?

Estas questões entrelaçam nossas propostas. Um currículo nômade nos ajuda a "compreender a escolarização como um mecanismo de poder, negociação e contestação" (BENNET apud GIROUX, 1995, p. 87). Nos ajuda também a compreender as maneiras como o poder opera, como as negociações são estabelecidas, mantidas, suspensas, e como a contestação age para “inventar" e construir as práticas docentes na sua dimensão social, pública. Isso porque o currículo nômade não se instala numa única posição ou tendência teórica. Ele vê os sujeitos em trânsito, sem identidades fixas e ousa inventar seus próprios trânsitos.

A perspectiva qualitativa contribui para pensarmos essa atitude nômade em contexto, constituída na cultura, no social. A cultura então, não é uma parte que se agrega à vida ou que se soma ao 'ser' e 'devir' dos sujeitos. É, então, uma dimensão que os/as faz e refaz. O caráter público das vivências docentes é prática, inteligência e memória coletiva, colaborativa, em que uns e outros - alunos e professores - se vêm, se observam e se transformam ao aprender.

Aprender e ensinar se modificam no espaço público porque são processos que expõem, discriminam e transformam os sujeitos. Como nos lembra Giroux, a pedagogia crítica é "uma prática cultural que só pode ser compreendida através de questões sobre história, política, poder e cultura" (1995, p. 87). O espaço público, "local adequado para a excelência humana"(ARENDT, 1995, p. 59), é o espaço onde aprendemos e ensinamos sobre nós, sobre as visualidades que nos configuram e sobre o mundo que vivemos e compartilhamos. Nele aprendemos que a arte condensa e, ao mesmo tempo, questiona, desafia e propõe representações e realidades. Ela pode criar vivências, trazê-las e uni-las na memória. A arte nos distingue como humanos mas não esconde nossa animalidade. Ela registra e constrói história, poder e cultura. A atitude nômade, a perspectiva qualitativa e o espaço público se articulam para reafirmar a condição humana 
da ação, pensamento, sentimento e trabalho que a arte exige, refina e transforma.

Voltamos à pergunta elaborada por Sousa Santos:"havendo tanto por criticar no mundo, porque se tornou tão difícil construir uma teoria crítica?” Ele responde:

encontro a resposta, por hora, em uma posição epistemológica e teórica tão distante do modernismo arrogante, incapaz de analisar a dimensão de sua própria crise, como de um pós-modernismo entreguista, rendido à celebração da sociedade que - apesar dos simulacros e das fragmentações - é globalmente injusta. Minha postura, que defino como pós-modernismo de oposição, parte da idéia central de que vivemos em um tempo caracterizado pela circunstância de eternos problemas modernos - as promessas não cumpridas da modernidade: liberdade, igualdade, solidariedade e paz - para os quais parece não haver soluções modernas (2005, p. 11).

A resposta de Sousa Santos nos orienta para pensar sobre as questões sugeridas por Arendt. Destacando as promessas não cumpridas da modernidade - liberdade, igualdade, solidariedade e paz - ele situa a história, a política, o poder e a cultura na esfera do público, da sociedade globalmente injusta. Mas sua discussão prossegue e nela a dimensão pública ganha ainda mais relevância pois é nela, na união entre teoria e ação, que Sousa Santos inscreve sua visão crítica em defesa de um pós-modernismo de oposição.

Não se limitando a uma teorização, o pós-modernismo de oposição é uma postura que guarda e impulsiona uma relação crítica entre reflexão e experiência e, ainda, entre razão e sentido. Quando o filósofo Marina afirma que um dos paradoxos que vivemos é a crença de "que o conhecimento é importante, mas são os sentimentos que nos fazem felizes ou desgraçados" (2004, p. 27), muitas histórias se encontram em nossas semelhanças e diferenças, permitindo que felizes e desgraçados possam "inventar” soluções pós-modernas para os problemas de liberdade, igualdade, solidariedade e paz.

Uma maneira de caminhar com estas questões é investir numa produção investigativa e docente no campo do ensino das artes visuais que nos faça mergulhar em histórias de vida, narrativas de experiências, práticas, concepções, lutas e esforços que 
Entre contingências e experiências vividas...

Propostas para pensar um ensino crítico de artes visuais

ajudem a compreender nossas contradições no contexto, também contraditório, dos processos que vivemos como professores de arte. Em outras palavras, este caminhar busca formas de compreender como agregamos, a um só tempo, fragmentos de tradição e de inovação, de trabalho e aventura, de método e capricho, de razão e afeto. Acompanhando a reflexão de Tourinho, acreditamos que "só nós podemos explicitar as contradições e conflitos incorporados ao saber e ao fazer arte na escola. Só nós conhecemos os tormentos e os prazeres dessas experiências" (2005, p. 117).

As três propostas críticas que apresentamos para pensar a construção de um currículo em artes visuais - uma consciência nômade, a radicalização da perspectiva qualitativa e, por fim, da esfera pública na educação - não esgotam, obviamente, o que este posicionamento exige de nós, docentes, investigadores e alunos. Não esgota porque tal posicionamento se caracteriza pela sua intenção de rever e reconstruir, continuamente, as próprias posições que o sustenta. Também não se esgota porque reconhecemos que a escola é apenas uma dentre as instituições que fazem - e desfazem - as possibilidades de transformação dos sujeitos e da sociedade que eles e elas constroem.

$\mathrm{Na}$ tentativa de ressaltar os desejos destas propostas, tomamos do músico Brian Eno (apud SEVCENKO, 2001, p. 91) uma idéia-caminho para concluir este trabalho. Ela sintetiza a necessidade de deslocamentos psicológicos, históricos, sociais, culturais e afetivos (do nomadismo), transgride com o imediatismo que nos pressiona e aprisiona (perspectiva qualitativa) e, finalmente, olha, com imaginação, para um futuro que, acreditamos, quer a nossa esperança (espaço público de ensinar e aprender). A idéia-síntese que deixamos para pensar um currículo em artes visuais é 'batalhar' pela fabricação - crítica - de um "GRANDE AQUI" e um "LONGO AGORA" das nossas experiências educativas e visuais.

\section{Nota}

1- O presente trabalho foi realizado com o apoio do CNPq, uma entidade do governo brasileiro voltada ao Desenvolvimento Científico e Tecnológico. 


\section{Referências Bibliográficas}

ALVAREZ, D. Frederico García Lorca y la Educación Artística: reflexiones a propósito de un centenário. III Jornades d'història de l'educació artística. Fernando Hernandez y Marta Ricart (Compiladores). Barcelona: Universitat de Barcelona, 1998, p.127-137.

ALZINA, R. B. La educación emocional em el marco de la orientación para el desarrollo humano. Humanismo para el siglo XXX - Propuestas para el Congresso Internacional. Bilbao: Universidad de Deusto, 2003, p.321-327.

APPLE, M. Ideology and Curriculum. New York: Routledge, 1990.

ARENDT, H. A Condição Humana. Rio de Janeiro: Forense, 1995.

AUGÉ, M. Não-Lugares: Introdução a uma antropologia da supermodernidade. Campinas: Papirus, 2003.

BACCEGA, M. A. "Recepção: Nova perspectiva nos estudos da comunicação". Comunicação \& Educação, Ano IV, nº. 12, maio/agosto, 1998, p.7-15.

BOLER, M. Disciplined Absences: Cultural Studies and the Missing Discourse of a Feminist Politics of Emotion. Michael Peters (Ed.). After the Disciplines The Emergence of Cultural Studies. London: Bergin \& Garvey, 1999, p.157-174.

BRAIDOTTI, R. Sujetos nômades. Barcelona: Paidós, 2000.

CARY, R. Critical Art Pedagogy - Foundations for Postmodern Art Education. New York: Garland Publishing, Inc.,1998.

CONDURU, R. Diálogos entre afro-brasilidade e arte contemporânea. Entrevista concedida a Fábio Lima e Lenice Barbosa. Jornal da FAV, Ano 4, N.8, junho de 2005, p.4-5.

CORAZZA, S. 0 que quer um currículo? Pesquisas Pós-Críticas em Educação. Petrópolis: Vozes, 2001.

CORAZZA, S. e TADEU, T. Composições. Belo Horizonte: Autêntica, 2003.

DENZIN, N. Interpretive Ethnography - Ethnographic Practices for the $\mathbf{2 1}^{\text {st }}$ Century. London: Sage, 1997.

DENZIN, N. \& Lincoln, Y. (Eds). The Landscape of Qualitative Research - Theories and Issues. London: Sage, 2003.

DUARTE JR. O Sentido dos Sentidos - A Educação (do) Sensível. Curitiba: Criar Edições, 2001.

EFLAND, A., FREEDMAN, K. \& STUHR, P. La educación en el arte posmoderno. Barcelona: Paidós, 2003. 
Entre contingências e experiências vividas...

Propostas para pensar um ensino crítico de artes visuais

FREEDMAN, K. Teaching Visual Culture. New York: Teachers College, 2003.

FREIRE, Paulo. Pedagogia do Oprimido, 39a edição. Ed. Paz e Terra, 2004.

Pedagogia da Autonomia: saberes necessários à prática educativa. São Paulo: Paz e Terra, 1996.

Educação como Prática da Liberdade, 20a edição. Rio de Janeiro: Paz e Terra, 1991.

GIROUX, H. Praticando estudos culturais nas Faculdades de Educação. Tomás Tadeu da Silva (org). Alienígenas na sala de aula - Uma introdução aos Estudos culturais em Educação. Petrópolis: Vozes, 1995, p.85-103.

GOODSON, I. Storying the Self. Preparing for postmodernity: The Peril and Promise. http://www. ivorgoodson.com/s-Postmodernity. Acessado em 24 de agosto de 2005.

HALL, S. The centrality of culture: notes on the cultural revolutions of our time. Kenneth Thompson (ed.). Media and cultural regulation. London: SAGE, 1997.

HERNANDEZ, F. A construção da subjetividade docente como base para uma proposta de formação inicial de professores de artes visuais. Marilda de Oliveira e Fernando Hernandez (Orgs.). A Formação do Professor e o Ensino das Artes Visuais. Santa Maria, RS: Editora UFSM, 2005, p.23-42.

. Las histórias de vida como estrategia de visibilización y generación de saber pedagógico. In: Ivor F. Goodson (Ed.) Histórias de Vida del Profesorado. Barcelona: Octaedro, 2004, p.9-26.

KINCHELOE, J. \& MCLAREN, P. Rethinking Critical Theory and Qualitative Research. Norman Denzin \& Yvonna Lincoln (eds.). The Landscape of Qualitative Research - Theory and Issues. London: Sage, 2003, p.433-488.

MARÇAL, I. El papel de las emociones en la historia de la Educación Artística. IV Jornades d'història de l'educació artística. Fernando Hernández, Roser Juanola y Laura Morejón (Compiladores). Barcelona: Universitat de Barcelona, 2001, p.245-255.

MARINA, J. A. Cronicas de la Ultramodernidad. Barcelona: Anagrama, 2004.

MARTINS, R. Educaçao e poder: deslocamentos perceptivos e conceituais da cultura visual. Marilda de Oliveira e Fernando Hernandez (Orgs.). A Formação do Professor e o Ensino das Artes Visuais. Santa Maria, RS: Editora UFSM, 2005, p.133-145.

MIRAVALLS, R. C. Educació de la dona durant el Franquisme. Els treballs manuals: des del silenci, la passitivitat, la submissió i el sacrifici. III Jornades d'història de l'educació artística. Fernando Hernandez y Marta Ricart (Compiladores). Barcelona: Universitat de Barcelona, 1998, p.301-313.

MONEDERO, J. C. Conciencia de Frontera: La Teoría Crítica Posmoderna de Boaventura de Sousa Santos. In: Sousa Santos. El milenio huérfano - ensayos 
para una nueva cultura política. Madrid: Editorial Trotta, 2005, p.15-93.

PADRÓ, C. Historia de museus, historia de prácticas educativas. V Jornades d'història de I'educació artística. Fernando Hernández i Laura Morejón (Compiladors). Barcelona: Universitat de Barcelona, 2003, p.23-40.

PASTOR, O. D. Para mi el dibujo era un relax. Reconstrucción de una clase de dibujo en la bachirellato de los años 50 . Trabajo de história oral. III Jornades d'història de l'educació artística. Fernando Hernandez y Marta Ricart (Compiladores). Barcelona: Universitat de Barcelona, 1998, p.293-299.

PRENSKY, M. "Digital Natives", "Digital Immigrants". Readings of the 21 st Century Literacy Summit. April 26-28, San José, California, 2005, p.77-82.

RUIZ, A. E. y MALANDA, D. F. El ideal de "lo bello" o la Educación Artística para la mujer. IV Jornades d'història de l'educació artística. Barcelona: Universitat de Barcelona, 2001, p.381-388.

SEVCENKO, N. A Corrida para o Século XXI - No loop da Montanha Russa. São Paulo: Companhia das Letras, 2001.

SILVA, T. T. O Currículo como Fetiche - a poética e a política do texto curricular. Belo Horizonte: Autêntica, 2001.

SOUSA SANTOS, B. Um Discurso sobre as Ciências. Lisboa: Afrontamento, 1999.

El milenio huérfano - ensayos para una nueva cultura política. Madrid: Editorial Trotta, 2005.

TOURINHO, I. Perguntas que conversam sobre educação visual e currículo. Marilda de Oliveira e Fernando Hernandez (Orgs.). A Formação do Professor e o Ensino das Artes Visuais. Santa Maria, RS: Editora UFSM, 2005, p.107-118.

VAN MANEN, M. Investigación Educativa y Experiencia Vivida. Barcelona: Idea Books, 2003.

VERÍSSIMO, L. F. Poesia numa hora destas? Jornal da Ciência, Ano XIX, N.555, $1 / 7 / 2005$, p.3. 


\section{Raimundo Martins e Irene Tourinho}

Raimundo Martins é professor titular da Faculdade de Artes Visuais da Universidade Federal de Goiás, FAV/UFG, doutor em Educação pela Southern Illinois University. Irene Tourinho é professora titular da Faculdade de Artes Visuais da Universidade Federal de Goiás, FAV/UFG, doutora em Educação pela Universidade de Wisconsin-Madison (EUA). Estão atualmente em pós-doutoramento na Unidade de Arte Educação do Departamento de Desenho da Faculdade de Bellas Artes da Universidade de Barcelona, Espanha, onde atuam também como professores visitantes. 